\title{
Factors affecting the detectability of voids by infrared thermography
}

\author{
P. Wyss' ${ }^{1}$, Th. Lüthi', R. Primas ${ }^{1}$ and O. Zogmal2
}

${ }^{1}$ Swiss Federal Laboratories for Materials Testing and Research (EMPA), Überlandstrasse 129, CH-8600 Dübendorf, Switzerland; ${ }^{2}$ ESEC SA, Hinterbergstrasse 32, P.O. Box 5050, CH-6330 Cham, Switzerland

\begin{abstract}
During the manufacturing of laminar plastics, debondings between layers can occur due to bad curing. Two inspection techniques by infrared thermography have to be considered: Impulse or transient thermography and lock-in thermograpy.

For both techniques, the detectability of a defect and the factors affecting it are major issues. The first investigated material is isotropic polyvinyl chloride, the second is anisotropic unidirectional carbon fiberreinforced plastic. This article will discuss the above mentioned factors and will derive some practical rules about the detectability of a defect.

For the two base materials analysed, the complex contrast is studied as a function of the defect diameter to depth ratio and the modulation frequency of the heating source. Practical rules will be derived and a comparison between the two techniques will be made.
\end{abstract}

\section{Introduction}

Laminar plastics such as woven fiber-reinforced plastics are becoming more and more widely used due to their good mechanical properties and their ability to be tailored to the intended application. During their manufacturing, debondings between layers can occur due to bad curing. Fiber-reinforced plastics in form of sheets are also used to reinforce civil engineering structures like bridges [1]. The presence of air inclusions or delaminations in the bonding layer between the sheet and the structure can drastically reduce the mechanical strength of the reinforcement. Therefore, a fast testing method is needed in order to detect such flaws. Until now, only the time consuming ultrasonic inspection method came into consideration. Infrared thermography is a particularly well suited inspection method, because it is fast and gives an image of the location of the defects. Two inspection techniques by infrared thermography have to be considered: the impulse or transient thermography [2] and the lock-in thermography [3].

\section{Experimental setup}

As defects act as thermal barriers, the thermal contrast between the temperature measured above a defect and the one measured on the sound material is dependent on the diameter $D$ of the defect, its depth $x$ and the thermal properties of the materials. The experiments were made with isotropic polyvinyl chloride (PVC) and unidirectional carbon fiber reinforced epoxy resin (CFRP); their thermal properties are summarized in table 1. It is to point out, however, that the thermal properties of CFRP are very strongly dependent on the fiber content and the fiber type [4].

\begin{tabular}{|c|c|c|c|c|}
\hline material & $\begin{array}{c}\text { density } \rho \\
{\left[\mathrm{kg} \mathrm{m}^{-3}\right]}\end{array}$ & $\begin{array}{c}\text { heat capacity c } \\
{\left[\mathrm{J} \mathrm{kg}^{-1} \mathrm{~K}^{-1}\right]}\end{array}$ & $\begin{array}{c}\text { thermal conductivity } \lambda \\
{\left[\mathrm{W} \mathrm{m}^{-1} \mathrm{~K}^{-1}\right]}\end{array}$ & $\begin{array}{c}\text { diffusivity } \alpha \\
{\left[\mathrm{m}^{2} \mathrm{~s}^{-1}\right]}\end{array}$ \\
\hline PVC & 1426 & 940 & 0.17 & $0.1310^{-6}$ \\
\hline CFRP T & 1350 & 1009 & 0.61 & $0.4510^{-6}$ \\
\hline CFRP II & 1350 & 1009 & 4.97 & $3.6510^{-6}$ \\
\hline
\end{tabular}

Table 1 : Thermal properties of PVC and CFRP

(The thermal diffusivity along the fibers for CFRP was taken from the literature) 
A front disc of the relevant material was put on a PVC back disc where the defect was simulated by a hole drilled in its center with a diameter $x$ between 3 and $10 \mathrm{~mm}$. A thermal paste provided a good thermal contact between the discs. By evacuating the air behind the second disk, the two are pressed uniformly and the hole simulates a perfect defect where the heat cannot flow. The front face of the cover disc was painted black in order to get an uniform and known value of the emissivity on the surface.

Figure 1 shows this experimental setup. The heating sources were:

for the impulse method two flash lamps with a total output energy of $6 \mathrm{~kJ}$ or $12 \mathrm{~kJ}$, with a distance of $0.3 \mathrm{~m}$ to the sample and an incidence angle of $45^{\circ}$,

for the lock-in method a halogen lamp with an electric power of $1 \mathrm{~kW}$, equipped with a filter in order to suppress the infrared radiation in the sensitivity range of the camera $(8-12 \mu m)$. The distance to the sample was $0.35 \mathrm{~m}$ and the angle of incidence $90^{\circ}$. This lock-in heating equipment was delivered by Agema.

The infrared camera used is an Agema 900 LW.

Due to the anisotropic behaviour of CFRP, the thermal image of a round shaped flaw is not a circle but more an oval [5]. Figure 2 illustrates this fact clearly.

Since the samples were analysed with both the impulse and the lock-in methods it is useful to review the relations between them.

Seidel [6] showed that the heat pulse can be approximately considered as a monochromic thermal wave with a time dependent diffusion-length $\mu_{\text {eff }}(t)$. Under this assumption, the thermal contrast $K(t)$ in the time domain is given by the absolute value of the complex contrast $K(f)$ obtained from the frequency domain where $\mu(f)$ is replaced by $\mu_{\text {eff }}(t)$. Table 2 summarizes the relations.

\begin{tabular}{|c|c|}
\hline Frequency domain & Time domain \\
\hline$\mu(f)=\sqrt{\frac{\alpha}{\pi f}}$ & $\mu_{\text {eff }}(t)=2 \sqrt{\alpha t}[7]$ \\
\hline$K(f)=K_{A}(f)+i K_{\phi}(f)$ & $K(t)=\left|K\left(f=\frac{1}{4 \pi t}\right)\right|$ \\
\hline
\end{tabular}

Table 2 : Relations between the frequency domain and the time domain

\section{Transient or impulse thermography}

The detection limit of impulse thermography depends on several parameters. By means of finite element computation and measurement the dependencies below were analysed:

1. the aspect ratio that means the ratio $D / x$, where $D$ is the diameter and $x$ the defect's depth

2. the anisotropy of the sample's material

3. the intensity of the heating pulse

Figure 3 displays the thermal contrast versus the aspect ratio for PVC as an example of isotropic plastic material. The thermal contrast diminishes faster, when the depth is varied while the diameter is being kept constant. The detection limit is $D / x=3$.

Figure 4 shows the thermal contrast versus the aspect ratio for unidirectional CFRP. The computed curves for the anisotropic material and the isotropic thought material with a thermal conductivity parallel to the fibers are close together and in good agreement with the measurement for the same heat pulse intensity. The isotropic material with a thermal conductivity perpendicular to the fibers (the resin only) would allow a quite better detectability than the computation suggests. In fact twice the intensity is needed to reach this detectability for the real CFRP sample.

It is well known that the limited slit response of the camera can also affect the detectability. Throughout these experiments, however, care was taken to keep this influence out.

\section{Lock-in thermography}

Due to the scanning frequency of the camera, only discrete heating frequencies are possible. For the following interpretations of the results, the absolute contrast values are not of interest. Figure 5 and 6 show the results for PVC (thickness $1 \mathrm{~mm}$ ) and CFRP (thickness $1.07 \mathrm{~mm}$ ), respectively. 
Both materials have a similar behavior, the results of the isotropic PVC, however, are less noisy. The contrast development behaves like a counter-clockwise slope in the negative phase contrast - positive amplitude contrast quarter of the respective coordinate system, beginning at or near the origin. The different curves are corresponding to the $D / x$-ratios, the different measurementpoints are corresponding to heating periods between 8.5 to $205 \mathrm{~s}$ for PVC and 4.3 to $51.2 \mathrm{~s}$ for CFRP, respectively (note that some long measurements are missing).

For PVC the third point of each slope corresponds to a period of $25.6 \mathrm{~s}$, equal to a thermal diffusion length of $1.03 \mathrm{~mm}$. With the exception of $\mathrm{D} / \mathrm{x}=3$, where all measurements are below a reliable value of phase, these measurements are clearly away from the origin. For CFRP the second point of each slope corresponds to a period of $8.53 \mathrm{~s}$, equal to a thermal diffusion length of $1.11 \mathrm{~mm}$, taking the thermal properties perpendicular to the fiber direction and $3.15 \mathrm{~mm}$ taking the other value. To take the first value seems more correct, as the relevant thermal diffusion length is for the direction perpendicular to the fiber. For both materials the amplitude contrast is low for small periods and the maximum contrast appears at a much larger period than the one corresponding to the thermal diffusion length of the defect, around $2.5 \mathrm{~mm}$ for PVC and around $2.0 \mathrm{~mm}$ for CFRP. Within the measurement uncertainty these statements are not influenced by the aspect ratio.

For the measurements on PVC, however, it seems that the aspect ratio is slightly influencing the slope, turning it counterclockwise for increasing values.

\section{Conclusions}

For the transient technique it was shown clearly that the heat input is influencing the detectability. For the lock-in technique similar experiments were not carried out; it is assumed, however, that the same would be true.

The maximum thermal contrast corresponds for both techniques to a similar thermal diffusion length, around 2 to 3 times larger than the effective defects depth. For the examined materials, for small heating periods with the lock-in technique the thermal contrast is mainly due to the phase contrast and detectable if the thermal diffusion length reaches the defects depth.

Therefore working with the transient technique, the operator will concentrate on the maximum thermal contrast with the disadvantage of having no precise information about the depth of the defect originating it. It can more exactly be found using the lock-in technique and concentrating on a growth of the phase contrast.

\section{Acknowledgments}

Mr. Zogmal is particularly indebted to Dr. Walther and Dr. Seidel, from the Friedrich-SchillerUniversity Jena (D), for very fruitful discussions.

\section{REFERENCES}

[1] MEIER (U.), DEURING (M.), MEIER (H.) and SCHWEGLER (G.). - Strengthening of structures with advanced composites. Clark (J.L.). Alternative Materials for the Reinforcement and Prestressing of concrete, Champman \& Hall, London, 1993, p. 153-171

[2] LAU (S.K.), ALMOND (D.P.), PATEL (P.M.), CORBETT (J.), QUIGLEY (M.B.C.). Analysis of transient thermal inspection. Infrared Technology and Applications, SPIE 1320, 1990

[3] BUSSE (G.), WU (D.) and KARPEN (W.). Thermal wave Imaging with phase sensitive modulated thermography. J. Appl. Phys. 71 \&, 1992, p. 3962-3965

[4] HANCOX (N.L.) and MAYER (R.M.). Design Data for Reinforced Plastics, A Guide for Engineers and Designers. Chapman \& Hall, London, 1994

[5] LÜTHI (Th.), MEIER (H.), PRIMAS (R.), ZOGMAL (O.). Infrared inspection of extermal bonded CFRP-sheets. Schickert (G.) and Wiggenhauser (H.) ed., Non-destructive testing in civil engineering (NDT-CE), DGZfP, Berlin, 1995, p. $689-696$

[6] SEIDEL (U.). Quantitative Auswertung photothermischer Messungen zur Erkennung und Charakterisierung von Inhomogenitäten in Festkörpern. Ph.D. thesis, Friedrich-SchillerUniversity, Jena, 1996 [in German] 
[7] LAU (S.K.), ALMOND (D.P.) and PATEL (P.M.). Transient thermal wave techniques for the evaluation of surface coatings. J. Phys. D: Appl. Phys. 24, 1991, p. 428-436

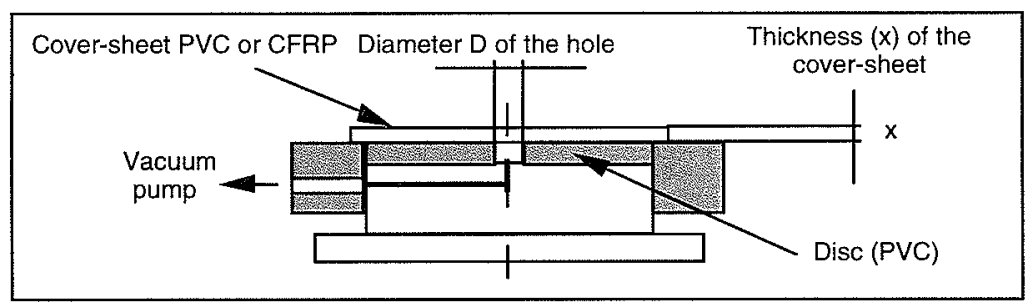

Fig. 1. Experimental setup


Fig. 2. Typical image of a circular void in a CFRP-sheet

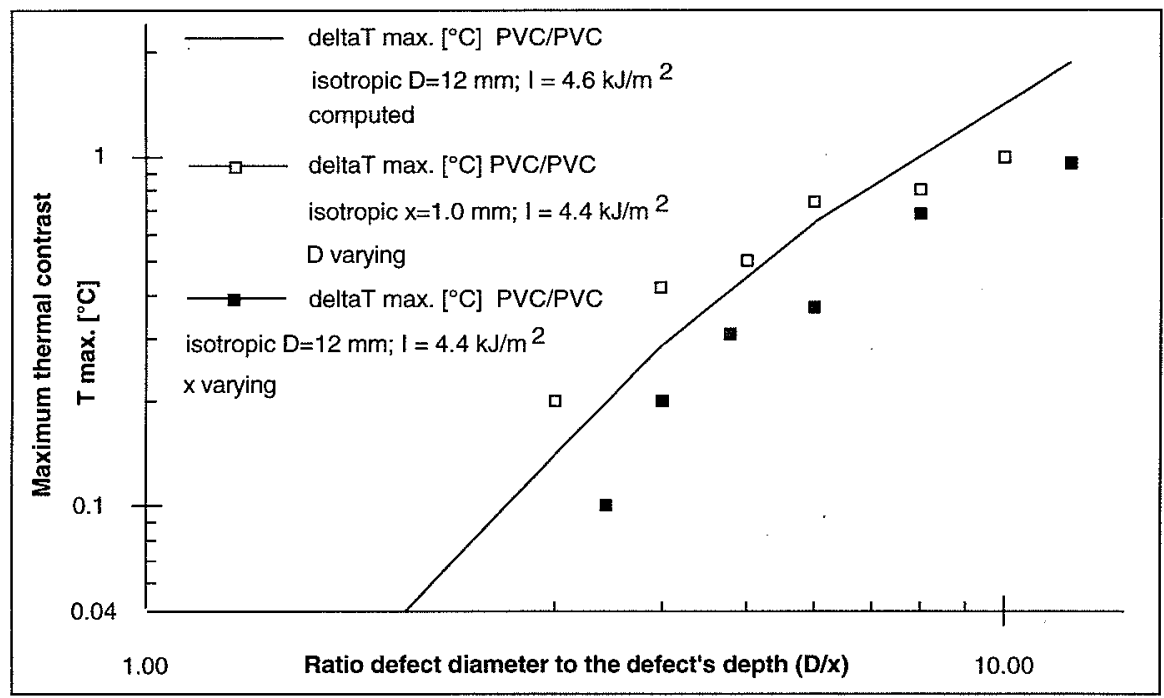

Fig. 3. Thermal contrast versus $\mathrm{D} / \mathrm{x}$ for $\mathrm{PVC}$ 
http://dx.doi.org/10.21611/qirt.1996.037



Fig. 4. Thermal contrast versus $D / x$ for $C F R P$

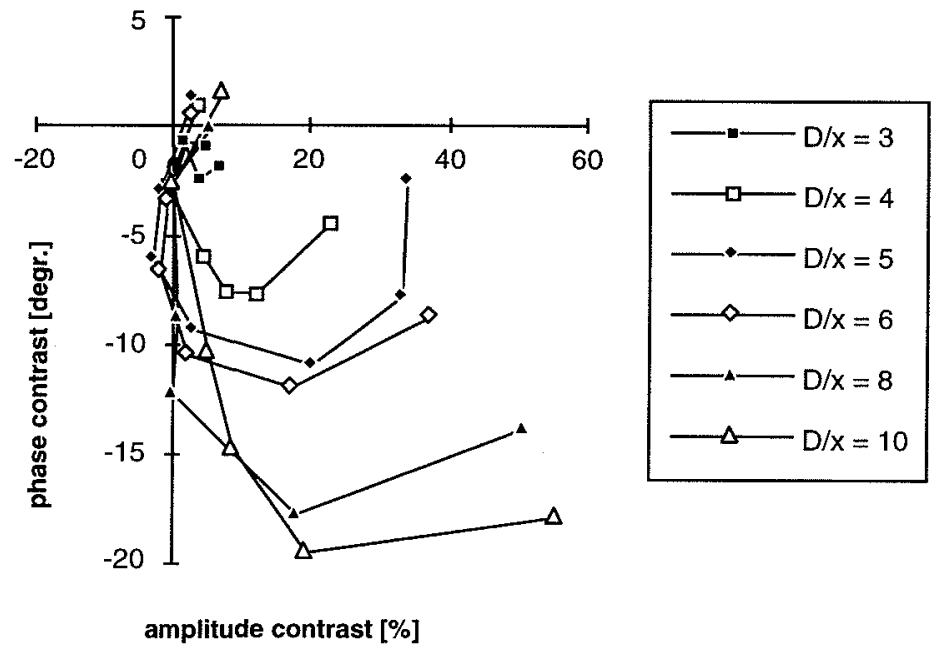

Fig. 5. Complex contrast development for PVC 
http://dx.doi.org/10.21611/qirt.1996.037

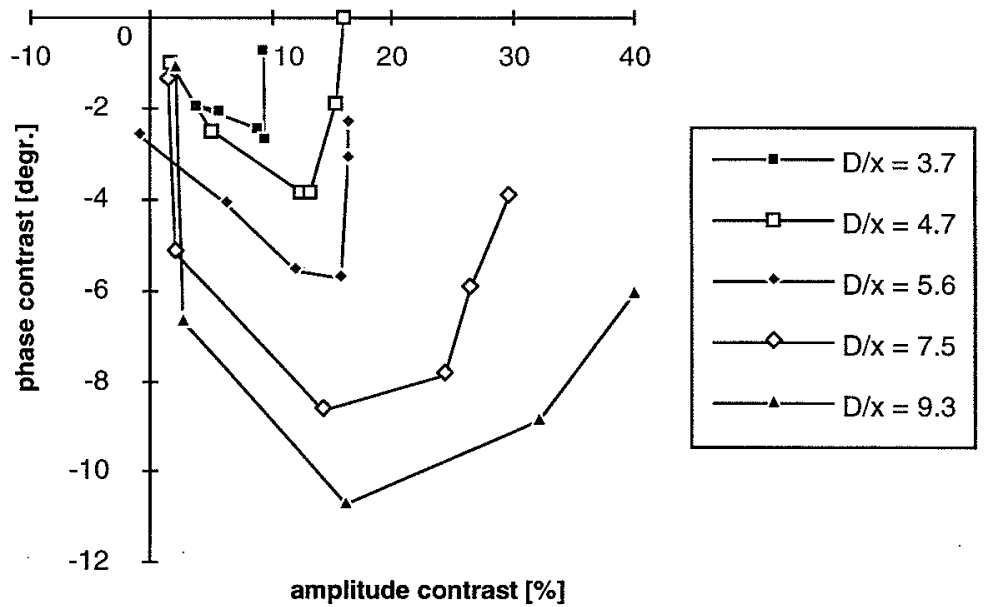

Fig. 6. Complex contrast development for CFRP 